\title{
Precise Phase and Amplitude Measurements on VLF Signals Propagated Through the Arctic Zone
}

\author{
F. H. Reder, ${ }^{2}$ C. J. $\AA$ Abom,${ }^{3}$ and G. M. R. Winkler ${ }^{2}$
}

(Received October 24, 1963)

\begin{abstract}
The scope and purpose of an Arctic VLF propagation study are outlined, and results are presented for the period from February to June 1963. Typical diurnal phase and amplitude patterns of NPM and NPG transmissions received at Stockholm are given for each month. The diurnal NPG amplitude change at Stockholm reached a maximum of $38 \mathrm{db}$ during March. Monthly averages of NPM-Stockholm and NPG-Stockholm diurnal phase changes are compared with those for other transmission paths. Twenty-four hour averages of frequency differences of VLF transmissions were measured at various reception sites and intercompared. Residual errors ranged from $10^{-11}$ to $3 \times 10^{-12}$, with standard deviations between 8.5 and $3.3 \times 10^{-11}$. Arctic paths were found to be worse by only a factor of about 2. Preliminary analysis of geomagnetic disturbance data and observed VLF phase anomalies indicates reasonable correlation for the NPG-Stockholm path. Finally, phase measurements on NBA taken simultaneously at Kiruna and Stockholm are compared. An SCNA event recorded by a Kiruna riometer clearly coincided with an NBA phase anomaly observed at Kiruna while the Stockholm NBA phase record showed no anomaly.
\end{abstract}

\section{Introduction}

This paper reports results of Arctic VLF propagation studies at Stockholm, Kiruna, and Fort Monmouth during the period from February to June 1963. The project is now being extended to an additional monitoring site near Fairbanks, Alaska, and is intended to continue until spring 1964, with special efforts during summer 1963 and winter $1963 / 64$.

Prime objective is more knowledge of the ionospheric $D$ layer in the Arctic because of its importance for the damping of radio signals in general, and the propagation of VLF waves in particular. Of interest are the diurnal and seasonal behavior of the $D$ layer, the influence of aurorae, polar cap absorptions (PCA), sudden commencements (SC), and magnetic phenomena on it, effects of $D$ layer disturbances and changes of ground conditions on VLF propagation, and the precision of VLF standardfrequency transfer. This information is to be derived from precise phase and amplitude measurements on stabilized VLF transmissions at several suitably located receiving sites.

Work is presently under way on direction-sensitive VLF antennas [Seeley, 1963] to allow comparison of VLF propagations along the shortest and longest great-circle paths, to control to some extent sferics reception, and to try to establish the correlation of some small observed phase variations with changes of the propagation direction under the influence of

1 This paper was presented at the VLF Symposium in Boulder, Colo., Aug. 14, 1963.

Institute for Exploratory Research, U.S. Army Electronies Research and Development Laboratory (USAELRDL), Fort Monmouth, N.J.

3 Research Institute of National Defence (FOA), Stockholm, Sweden. ionospheric disturbances. Reception of the two NPM or NPG sionals at Stockholm would be of particular interest since it would provide a means of simultaneous study of Arctic and Antarctic disturbances at one spot. Direct and antipodal signal receptions would also provide one of the best means to establish the limit of precision of VLF standardfrequency transfer.

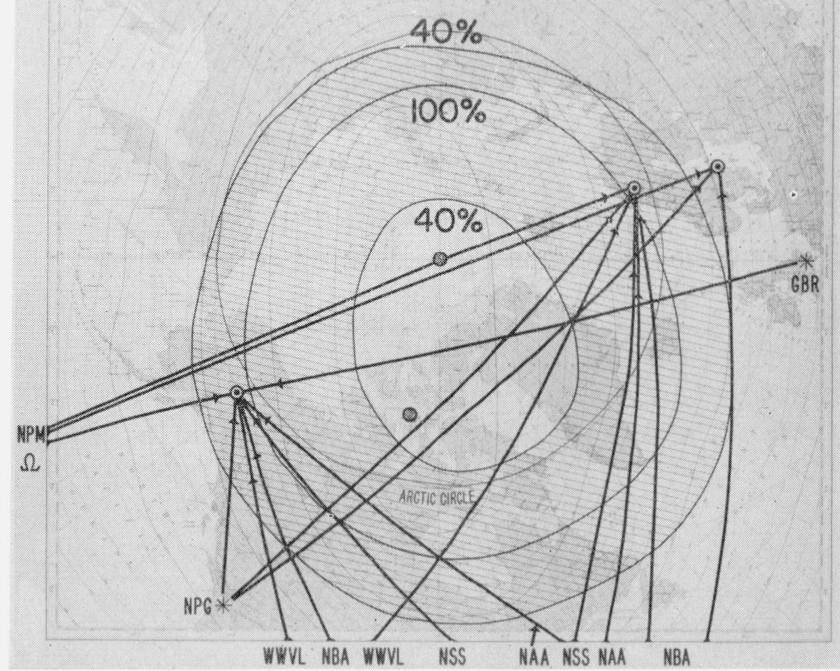

Figure 1. Geographic locations of VLF transmitters and receiving sites with respect to each other, to auroral zone, geographic pole, and magnetic inclination pole. 
The relative posit ons of our present receiving sites with respect to monitored VLF transmitters, NPM, Haiku, ${ }^{4}$ NPG, NBA, NSS, NAA, and GBR are shown in figure 1 and tables 1 and 2 .

TABLE 1. Geographic and geomagnetic coordinates of VLF transmitters and receiving sites

\begin{tabular}{|c|c|c|c|c|}
\hline \multirow{2}{*}{ Locations } & \multicolumn{2}{|c|}{ Geogr. coordin. } & \multicolumn{2}{|c|}{ Geomagn. coordin. } \\
\hline & Long. & Lat. & Long. & Lat. \\
\hline NPM $\ldots . .$. & $158^{\circ} \mathrm{W}$ & $21^{\circ} \mathrm{N}$ & $266^{\circ}$ & $21^{\circ} \mathrm{N}$ \\
\hline Fairbanks . & $148^{\circ} \mathrm{W}$ & $65^{\circ} \mathrm{N}$ & $258^{\circ}$ & $65^{\circ} \mathrm{N}$ \\
\hline NPG $\ldots$ & $122^{\circ} \mathrm{W}$ & $48^{\circ} \mathrm{N}$ & $296^{\circ}$ & $54^{\circ} \mathrm{N}$ \\
\hline NBA & $80^{\circ} \mathrm{W}$ & $09^{\circ} \mathrm{N}$ & $350^{\circ}$ & $20^{\circ} \mathrm{N}$ \\
\hline NSS ..... & $77^{\circ} \mathrm{W}$ & $39^{\circ} \mathrm{N}$ & $352^{\circ}$ & $50^{\circ} \mathrm{N}$ \\
\hline Ft. Monmouth_. & $74^{\circ} \mathrm{W}$ & $40^{\circ} \mathrm{N}$ & $356^{\circ}$ & $52^{\circ} \mathrm{N}$ \\
\hline NAA $\ldots$ & $67^{\circ} \mathrm{W}$ & $45^{\circ} \mathrm{N}$ & $04^{\circ}$ & $57^{\circ} \mathrm{N}$ \\
\hline GBR $\ldots$ & $01^{\circ} \mathrm{W}$ & $52^{\circ} \mathrm{N}$ & $85^{\circ}$ & $54^{\circ} \mathrm{N}$ \\
\hline Stockholm_-_. & $18^{\circ} \mathrm{E}$ & $29^{\circ} \mathrm{N}$ & $107^{\circ}$ & $58^{\circ} \mathrm{N}$ \\
\hline Kiruna . . & $20^{\circ} \mathrm{E}$ & $68^{\circ} \mathrm{N}$ & $116^{\circ}$ & $65^{\circ} \mathrm{N}$ \\
\hline
\end{tabular}

TABLE 2. Distances in kilometers between VLF transmitters and receiving sites

\begin{tabular}{l|r|r|r|r}
\hline \hline \multicolumn{1}{r|}{ Locations } & Fairbanks & Ft Monm. & Kiruna & \multicolumn{1}{|c}{ Stockholm } \\
\cline { 1 - 2 } \cline { 1 - 2 } NPM & 4,900 & 8,000 & 10,100 & 11,100 \\
NPG & 2,500 & 3,800 & 6,800 & 7,600 \\
NBA & 8,300 & 3,500 & 9,500 & 9,500 \\
NSS & 5,400 & 240 & 6,400 & 6,700 \\
NAA & 5,300 & 750 & 5,400 & 5,700 \\
GBR & 6,800 & 5,700 & 2,100 & 1,400 \\
\hline
\end{tabular}

The following features of this network are of interest:

1. Propagation of signals from Oahu, Hawaii (NPM, Haiku), to Stockholm and Kiruna provide occasionally up to three simultaneous frequencies $(19.8,13.2$ or 14.2 , and $10.2 \mathrm{kc} / \mathrm{s}$ ) over a common Arctic propagation route of maximum length.

2. Comparison of the Fairbanks and Kiruna data will give results for either an all-sunlight (summer) or all-dark (winter) Arctic path.

3. Simultaneous NBA receptions at Kiruna and Stockholm allow comparison of two propagations from the same station over paths of almost identical distances, but with one traversing the zone of most frequent auroras and the other one lying outside the outer 40 percent ring.

All stations utilize commercial automatic phase and amplitude tracking receivers and are controlled by atomic frequency standards [Reder, 1963].

\section{Diurnal Phase and Amplitude Variations}

A preliminary analysis of monthly variations of diurnal time-of-arrival (TOA) ${ }^{5}$ changes observed

${ }^{4}$ Haiku is one station of the Navy's experimental Omega VLF navigation system. It is located on Oahu, Hawaii.

5 TOA is defined as phase difference, $(\phi \mathrm{LOC}-\phi \mathrm{REC})$, divided by angular VLF frequency, $\omega$.
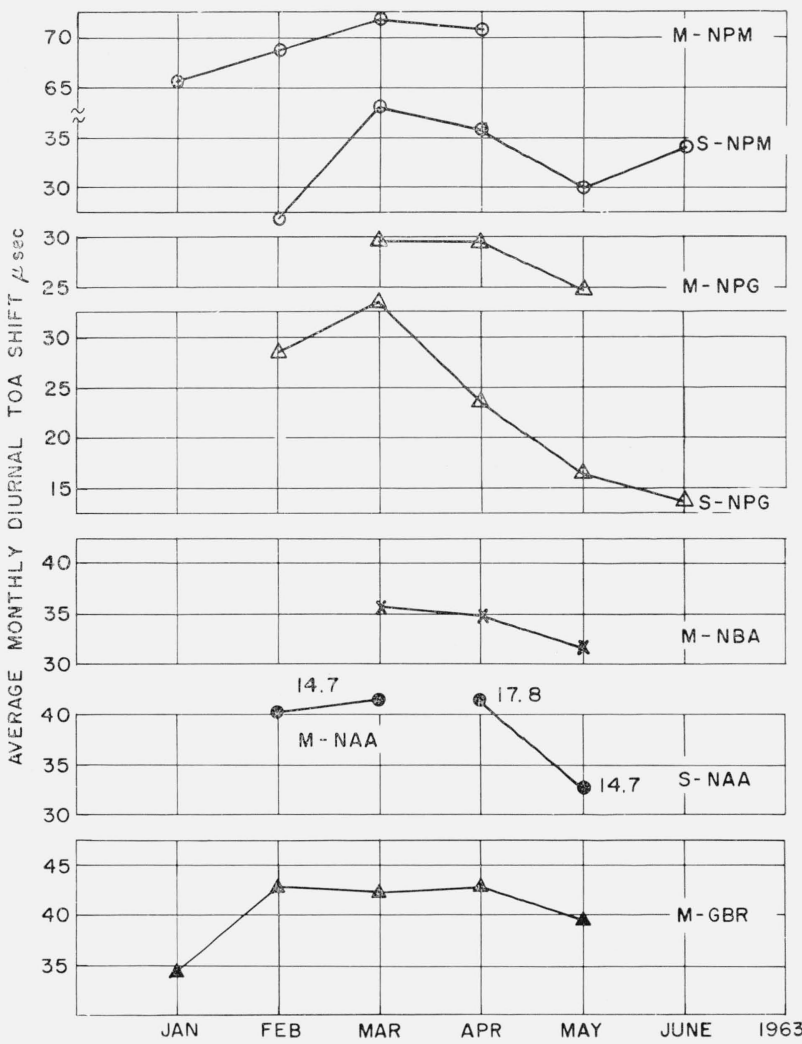

Figure 2. Monthly variation of average TOA trapezoid heights.

during the past six months at Fort Monmouth (M), Stockholm (S), and Kiruna (K) is listed in table 3 and illustrated in figure 2. All curves of figure 2 show a tendency of increasing diurnal variation until March and decreasing variation thereaiter. This is most pronounced for the NPG $\rightarrow \mathrm{S}$ path. The steady increase until March reflects the gradual decrease of the daylight $D$ layer altitude as solar illumination became more effective in the Northern Hemisphere. The large drop of the $\mathrm{NPG} \rightarrow \mathrm{S}$ curve aifter March was caused by the change of this path

TABLE 3. Diurnal TOA shifts of VLF transmissions measured at various sites in 1963

All numbers refer to microseconds, except numbers in parentheses are numbers of days for which TOA trapezoids were available

\begin{tabular}{|c|c|c|c|c|c|c|c|}
\hline $\begin{array}{l}\text { Sta- } \\
\text { tion }\end{array}$ & Jan & Feb & Mar & Apr & May & June & Receiver \\
\hline NPM & $65.6(10)$ & \begin{tabular}{l}
$68.7(09)$ \\
$26.9(\mathrm{C} 7)$ \\
\hdashline-
\end{tabular} & \begin{tabular}{ll}
71.7 & $(28)$ \\
38.6 & $(27)$ \\
\hdashline
\end{tabular} & $\mid \begin{array}{rr}70.9 & (20) \\
35 . & (26) \\
- & \end{array}$ & $29.9(08)$ & $\begin{array}{l}34.0 \\
30.5(10) \\
066)\end{array}$ & $\begin{array}{l}\text { Ft. Monm. } \\
\text { Stockholm } \\
\text { Kiruna }\end{array}$ \\
\hline NPG & & $28.5(03)$ & \begin{tabular}{ll}
29.7 & $(06)$ \\
33.1 & $(19)$ \\
\hdashline & -
\end{tabular} & $\begin{array}{r}29.5(06) \\
23.5(15) \\
-\end{array}$ & \begin{tabular}{l}
$24.8(06)$ \\
$16.5(28)$ \\
\hdashline
\end{tabular} & $\begin{array}{l}13.6(11) \\
18.5(04)\end{array}$ & $\begin{array}{l}\text { Ft. Monm. } \\
\text { Stockholm } \\
\text { Kiruna }\end{array}$ \\
\hline NBA & & & \begin{tabular}{l}
$35.7(17)$ \\
\hdashline-
\end{tabular} & $\mid \begin{array}{c}34.7(22) \\
-\end{array}$ & $31.3(03)$ & $\begin{array}{l} \\
66.0 \\
43.4(02)\end{array}$ & $\begin{array}{l}\text { Ft. Monm. } \\
\text { Stockholm } \\
\text { Kiruna }\end{array}$ \\
\hline NAA & & $40.0(02)$ & $41.4(07)$ & * $41.3(06)$ & $32.5(21)$ & - & $\begin{array}{l}\text { Ft. Monm. } \\
\text { Stockholm }\end{array}$ \\
\hline GBR & $34.4(10)$ & $43.0(01)$ & 42.2 (21) & $42.9(22)$ & $39.3(06)$ & -... & Ft. Monm. \\
\hline
\end{tabular}

*NAA operated on $17.8 \mathrm{kc} / \mathrm{s}$ during this period. 

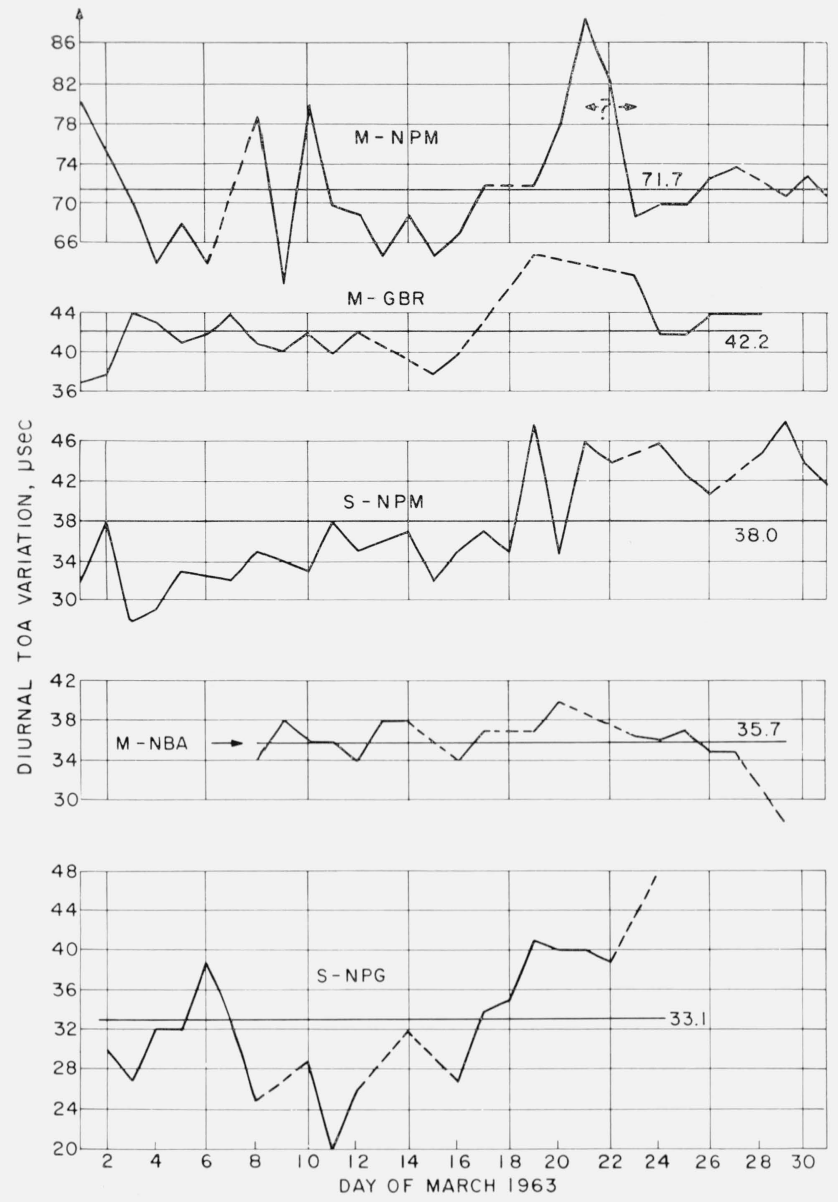

Figure 3. Daily variation of VLF TOA trapezoid heights during March 1963.

from periodic nighttime condition along 100 percent of its length in winter to only about 15 percent in summer. Figure 3 depicts diurnal TOA changes from day to day during March 1963 and it can be seen that trapezoid height variations of 5 or even more than $10 \mu \mathrm{sec}$ within $24 \mathrm{hr}$ were not uncommon.

Typical diurnal TOA and amplitude patterns for $\mathrm{NPM} \rightarrow \mathrm{S}$ and $\mathrm{NPG} \rightarrow \mathrm{S}$, observed between February and May 1963, are shown in figures 4 through 9. The most distinct feature of the patterns of figure 4 is the appearance of deep minima during March at about $1600 .{ }^{6}$ The minima correspond to the very brief intervals between 1600 and 1700 in March when the $D$ laver along the $\mathrm{NPM} \rightarrow \mathrm{S}$ path was completely illuminated and its ground projection fell into the twilight zone [Adams and Whitehead, 1960] as demonstrated in figure 5. For the remainder of March the path was partially in shadow except for a brief all-dark period.

The diurnal variation of the NPM amplitude at Stockholm ranged from 8 to $14 \mathrm{db}$, with maximum variation in March (fig. 6). Significant is the amplitude pattern on 25 and 26 February between 0400 and 0700 (midnight), and in particular between 1600 and 1800 when the path was at first briefly all
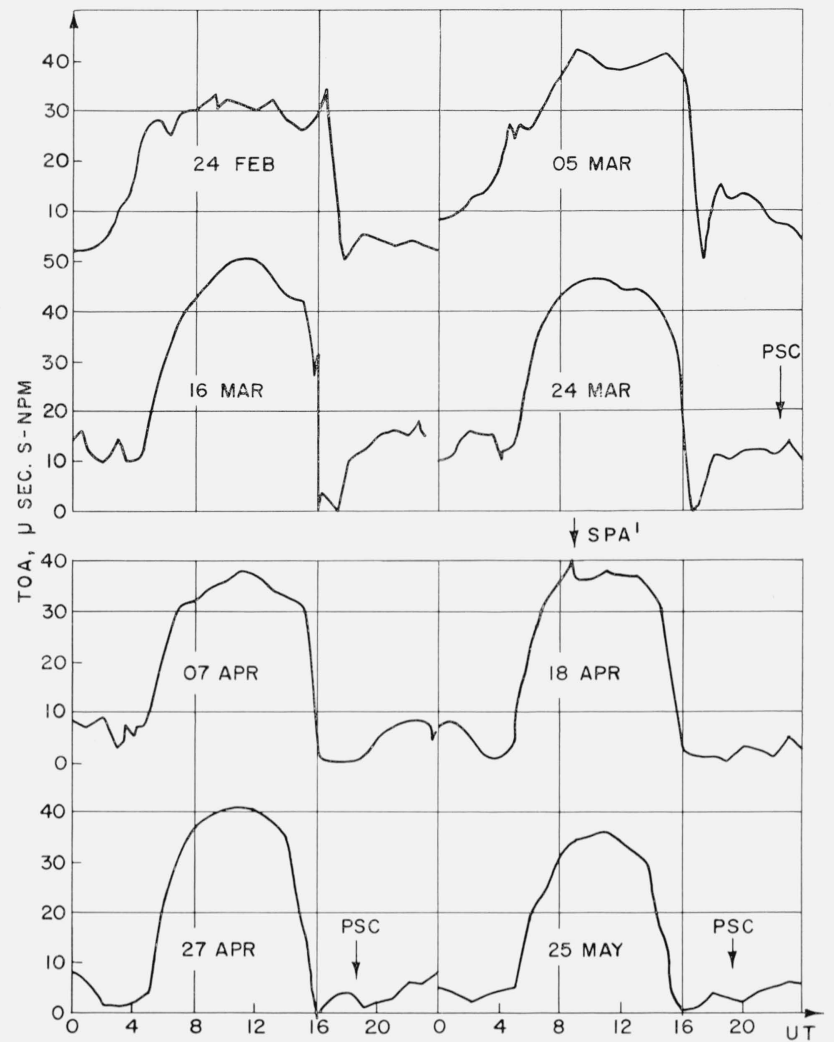

FIgure 4. Typical diurnal TOA patterns of NPM signals observed at Stockholm between February and May 1963.

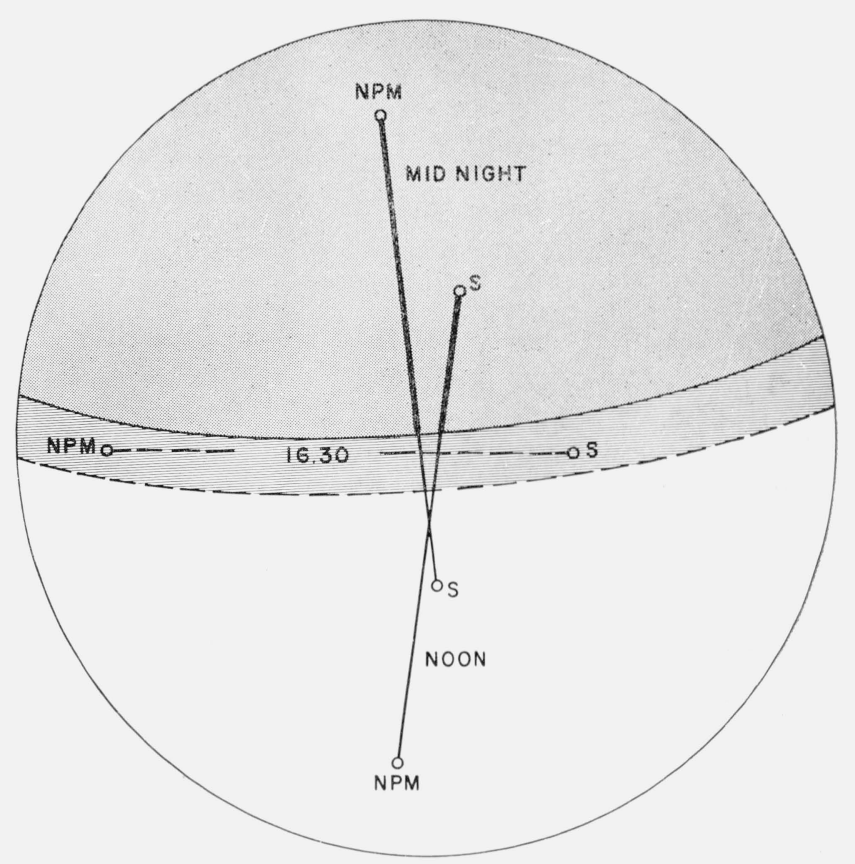

Figure 5. Various phases of illumination of the NPM-toStockholm path on 25 February 1963. 


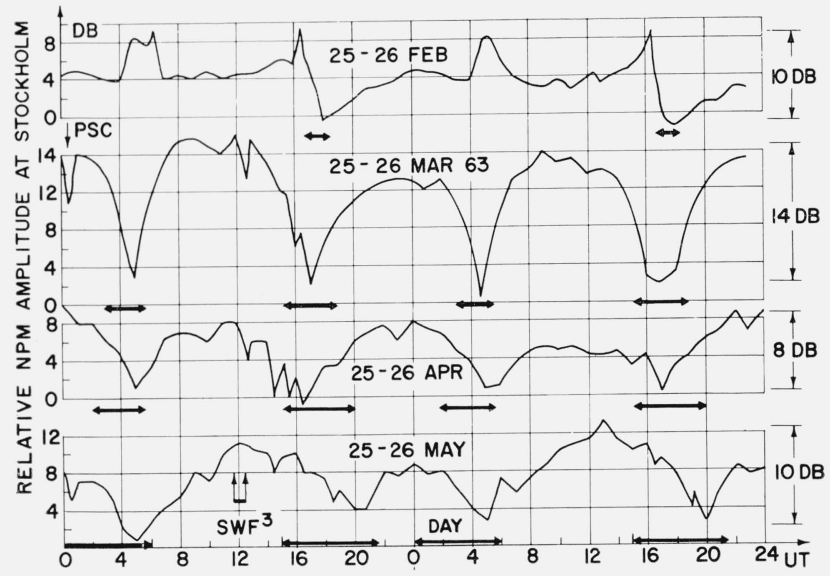

Figure 6. Typical diurnal amplitude patterns of NPM signals observed at Stockholm between February and May 1963.
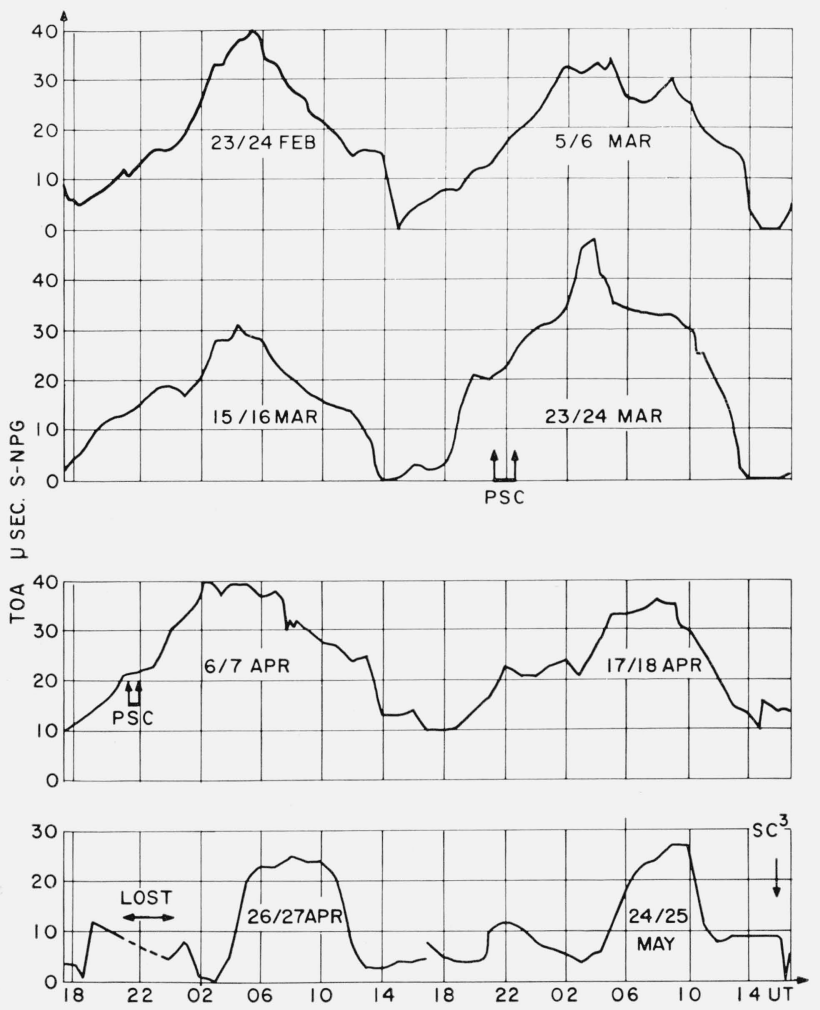

Figure 7. Typical diurnal TOA patterns of NPG signals observed at Stockholm between February and May 1963.

in shadow and then immediately all in sunlight before the generally encountered mixed illumination conditions set in.

The TOA patterns for $\mathrm{NPG} \rightarrow \mathrm{S}$ (fig. 7) show a much larger change of diurnal variation, are more disturbed - possibly because the $(\mathrm{NPG} \rightarrow \mathrm{S})$ path lies close to the magnetic dip pole-, and have more structural complexity during April and May when the two path ends have separate night conditions as can be demonstrated in a fashion similar to that of figure 5 .

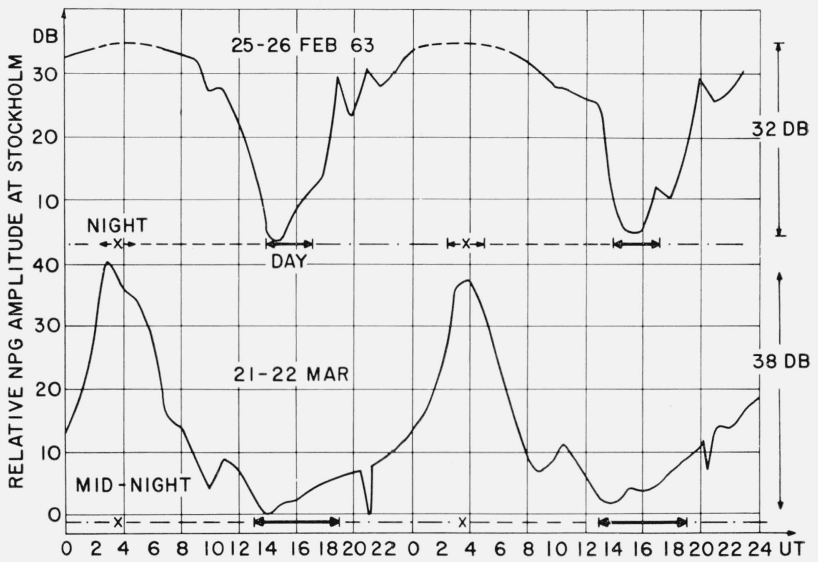

Figure 8. Typical diurnal amplitude patterns of NPG signals received at Stockholm in February and March 1963.

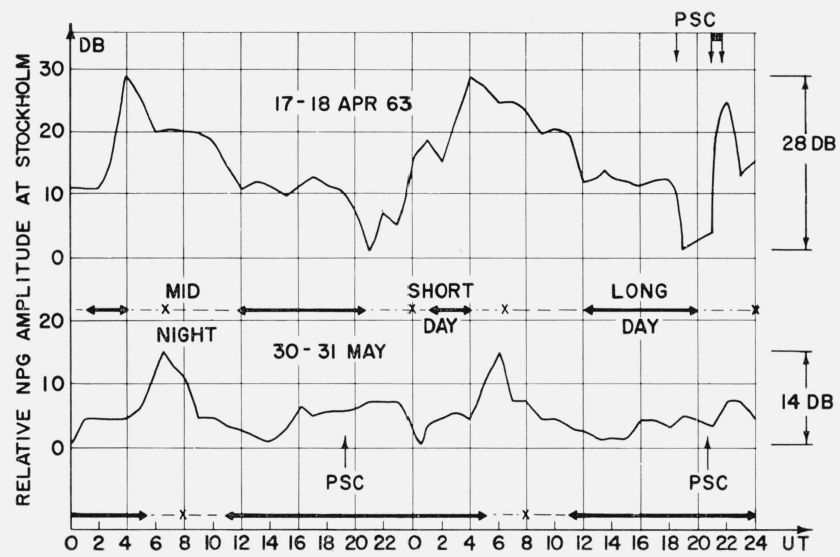

Figure 9. Typical diurnal amplitude patterns of NPG signals received at Stockholm in April and May 1963.

The NPG diurnal amplitude variation at Stockholm ranged from $38 \mathrm{db}$ around the middle of March to $14 \mathrm{db}$ at the end of May (figs. 8 and 9). No explanation can yet be offered for the excessive diurnal amplitude change during February and March. It was first believed to be caused by a poor definition of the daylight $D$ layer near the twilight zone at high latitudes. But this is not confirmed by the behavior of the $\mathrm{NPM} \rightarrow \mathrm{S}$ path as can be seen from figures 5 and 6 .

It should be noted here that the amplitude curves do not reproduce true seasonal variations, since no absolute field strength measurement equipment was available until now. It is also worth mentioning that the $\mathrm{NPG} \rightarrow \mathrm{S}$ path crosses an icecap of over $2,000 \mathrm{~m}$ thickness and $900 \mathrm{~km}$ length, whereas the $\mathrm{NPM} \rightarrow \mathrm{S}$ path does not. How much this contributed to the relatively poor reception of NPG at Stockholm will be better understood after completion of absolute amplitude measurements during summer 1963. 


\section{Precision of VLF Standard-Frequency Transfer}

Next we shall compare the $24 \mathrm{hr}$ averages of VLF measurements of the difference frequencies (NPGNPM) made at Fort Monmouth and Stockholm with data distributed monthly by J. Pierce. And we shall do the same with (GBR-NBA) data taken at Fort Monmouth and NBS, Boulder (table 4). The average residual errors fell within $\pm 10^{-11}$, and the standard deviations were smaller than $\pm 9 \times 10^{-11}$. It is obvious from the data that - contrary to expectation-Arctic transmissions compare quite favorably with those along other paths.

TABLE 4. Averages and standard deviations, $\sigma$, of residual errors of different frequencies $(N P G-N P M)$ and $(G B R-N B A)$ measured by FOA at Stockholm, by USAELRDL at Fort Monmouth, by Pierce at Cambridge, and by NBS at Boulder

\begin{tabular}{|c|c|c|c|}
\hline \multirow{2}{*}{$\begin{array}{l}\text { Difference of } \\
\text { VLF trans- } \\
\text { missions }\end{array}$} & \multirow{2}{*}{ Compared between } & \multicolumn{2}{|c|}{ Residual error } \\
\hline & & $\begin{array}{l}\text { Avg. } \\
(\Delta f / f) \times 10^{11}\end{array}$ & $\sigma(\Delta f / f) \times 10^{11}$ \\
\hline NPG-NPM & $\begin{array}{l}\text { Stockholm-Cambridge (all) } \\
\text { Stockholm-Cambridge ( } 3 \text { excl)* } \\
\text { Monmouth-Cambridge (all) }\end{array}$ & $\begin{array}{l}+1 \\
-1 \\
+0.6\end{array}$ & $\begin{array}{l}8.3 \\
5.9 \\
8.5\end{array}$ \\
\hline GBR-NBA & $\begin{array}{l}\text { Monmouth-Cambridge (all) } \\
\text { Monmouth-Cambridge (1 excl)* } \\
\text { Boulder-Cambridge (all) }\end{array}$ & $\begin{array}{l}-0.5 \\
+0.6 \\
-0.3\end{array}$ & $\begin{array}{l}5.5 \\
3.9 \\
3.3\end{array}$ \\
\hline
\end{tabular}

*Excluded measurements deviated excessively from average.

\section{Correlation of VLF Phase Anomalies With Ionospheric and Geomagnetic Disturbances}

An attempt was made to see if sudden commencements (SC) and geomagnetic phenomena, internationally reported for the period from February to May 1963 at Darmstadt and Paris, could be correlated with almost simultaneously (up to few minutes delay) observed phase anomalies on various VLF paths. Table 5 shows that geomagnetic phenomena could, in the average, definitely not be detected as immediate VLF phase anomalies in only 37 percent of the analyzed data, and that this figure drops to 24 percent if one excludes the rather insensitive paths, $\mathrm{NPM} \rightarrow \mathrm{M}, \mathrm{NBA} \rightarrow \mathrm{M}$, and $\mathrm{GBR} \rightarrow \mathrm{M}$.

Table 6 indicates the sensitivity of the various propagation paths to geomagnetic disturbances. Here it is suspected that the $\mathrm{NPG} \rightarrow \mathrm{M}$ path will fall behind the $\mathrm{NPG} \rightarrow \mathrm{S}$ path when more data on $\mathrm{NPG} \rightarrow \mathrm{M}$ have become available. The few solar disturbances reported during the period of this study tend to show that the NPM $\rightarrow \mathrm{M}$ path is most affected due to its long West-East extension in medium latitudes, whereas the $\mathrm{NBA} \rightarrow \mathrm{M}$ and $\mathrm{GBR} \rightarrow \mathrm{M}$ paths are least affected.

TABLE 6. Listing of VLF paths according to decreasing sensitivity to geomagnetic and sudden ionospheric disturbances

\begin{tabular}{|c|c|c|c|}
\hline \multicolumn{2}{|c|}{ Geomagnetic phenomena } & \multicolumn{2}{|c|}{ Sudden ionospheric disturbances } \\
\hline Path & $\%^{*}$ & Path & $\%^{*}$ \\
\hline $\begin{array}{l}\mathrm{NPG} \rightarrow \mathrm{M} \\
\mathrm{NPG} \rightarrow \mathrm{S} \\
\mathrm{NAA} \rightarrow \mathrm{S} \\
\mathrm{NAA} \rightarrow \mathrm{M} \\
\mathrm{NPM} \rightarrow \mathrm{S} \\
\mathrm{NPM} \rightarrow \mathrm{M} \\
\mathrm{GBR} \rightarrow \mathrm{M} \\
\mathrm{NBA} \rightarrow \mathrm{M}\end{array}$ & $\begin{array}{l}82 \\
79 \\
74 \\
67 \\
66 \\
58 \\
45 \\
34\end{array}$ & $\begin{array}{l}\mathrm{NPM} \rightarrow \mathrm{M} \\
\mathrm{NPG} \rightarrow \mathrm{S} \\
\mathrm{NAA} \rightarrow \mathrm{S} \\
\mathrm{NPM} \rightarrow \mathrm{S} \\
\mathrm{NBA} \rightarrow \mathrm{M} \\
\mathrm{GBR} \rightarrow \mathrm{M}\end{array}$ & 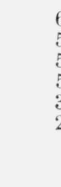 \\
\hline
\end{tabular}

Figures 10, 11, and 12 depict typical forms of TOA perturbations caused by bays with pulsating or sudden begin (PSC), and short wave fade outs (SWF). These effects are larger at the lower frequencies due to higher phase velocities of propagation [Wait, 1962]. They exceeded very rarely 10 $\mu$ sec for magnetic disturbances while they relatively often fell between 10 and $20 \mu$ sec for solar disturbances. Solar ionospheric perturbations - except aurorae and rare proton flare effects - do not affect VLF night paths. This influences somewhat the ionospheric graduation scale of table 6 which is otherwise strongly controlled by the sun's zenith angle at the path center [Chilton, Crombie, and Jean, 1962].

TABLE 5. Numbers of geomagnetic phenenomena and sudden ionospheric disturbances observed as phase anomalies on various VLF transmission paths during first half of 1963

\begin{tabular}{|c|c|c|c|c|c|c|c|c|}
\hline \multirow{2}{*}{ Influence observed on } & \multirow{2}{*}{$*$} & \multicolumn{4}{|c|}{ Geomagnetic phenomena } & \multicolumn{3}{|c|}{$\begin{array}{l}\text { Sudden ionospheric } \\
\text { disturbances }\end{array}$} \\
\hline & & Yes & Possibly & $\begin{array}{c}\text { Very } \\
\text { distbd. }\end{array}$ & No & Yes & Possibly & No \\
\hline $\begin{array}{l}\mathrm{NPM} \rightarrow \mathrm{S} \\
\mathrm{NPM} \rightarrow \mathrm{M} \\
\mathrm{NPG} \rightarrow \mathrm{S} \\
\mathrm{NPG} \rightarrow \mathrm{M} \\
\mathrm{NAA} \rightarrow \mathrm{S} \\
\mathrm{NAA} \rightarrow \mathrm{M} \\
\mathrm{NBA} \rightarrow \mathrm{M} \\
\mathrm{GBR} \rightarrow \mathrm{M}\end{array}$ & $\begin{array}{l}\mathrm{N}(\%) \\
\mathrm{N}(\%) \\
\mathrm{N}(\%) \\
\mathrm{N}(\%) \\
\mathrm{N}(\%) \\
\mathrm{N}(\%) \\
\mathrm{N}(\%) \\
\mathrm{N}(\%)\end{array}$ & $\begin{array}{l}29(44) \\
10(20) \\
21(31) \\
06(27) \\
08(35) \\
01(17) \\
00(00) \\
11(20)\end{array}$ & $\begin{array}{l}19(29) \\
19(38) \\
16(24) \\
12(55) \\
09(39) \\
03(50) \\
10(26) \\
14(25)\end{array}$ & $\begin{array}{l}01(01) \\
16(24)\end{array}$ & $\begin{array}{l}17(26) \\
21(42) \\
14(21) \\
04(18) \\
06(26) \\
02(33) \\
26(66) \\
30(55)\end{array}$ & $\begin{array}{l}05(28) \\
03(34) \\
06(33) \\
02(33) \\
03(30) \\
03(27)\end{array}$ & $\begin{array}{l}04(22) \\
03(33) \\
03(17) \\
01(17)\end{array}$ & $\begin{array}{l}09(50) \\
03(33) \\
09(50) \\
01(100) \\
03(50) \\
07(70) \\
08(73)\end{array}$ \\
\hline Total & $\mathrm{N}(\%)$ & $86(26)$ & $102(31)$ & $20(6)$ & $120(37)$ & $22(30)$ & $11(15)$ & $40(55)$ \\
\hline Partial total** & $\mathrm{N}(\%)$ & $65(35)$ & $59(32)$ & $17(9)$ & $43(24)$ & & & \\
\hline
\end{tabular}

${ }^{*} \mathrm{~N}=$ number of observations.

\% Holds for each specific path, e.g., NPM $\rightarrow$ S, except in "Total" lines.

$* *$ Except $\mathrm{NPM} \rightarrow \mathrm{M}, \mathrm{NBA} \rightarrow \mathrm{M}, \mathrm{GBR} \rightarrow \mathrm{M}$. 


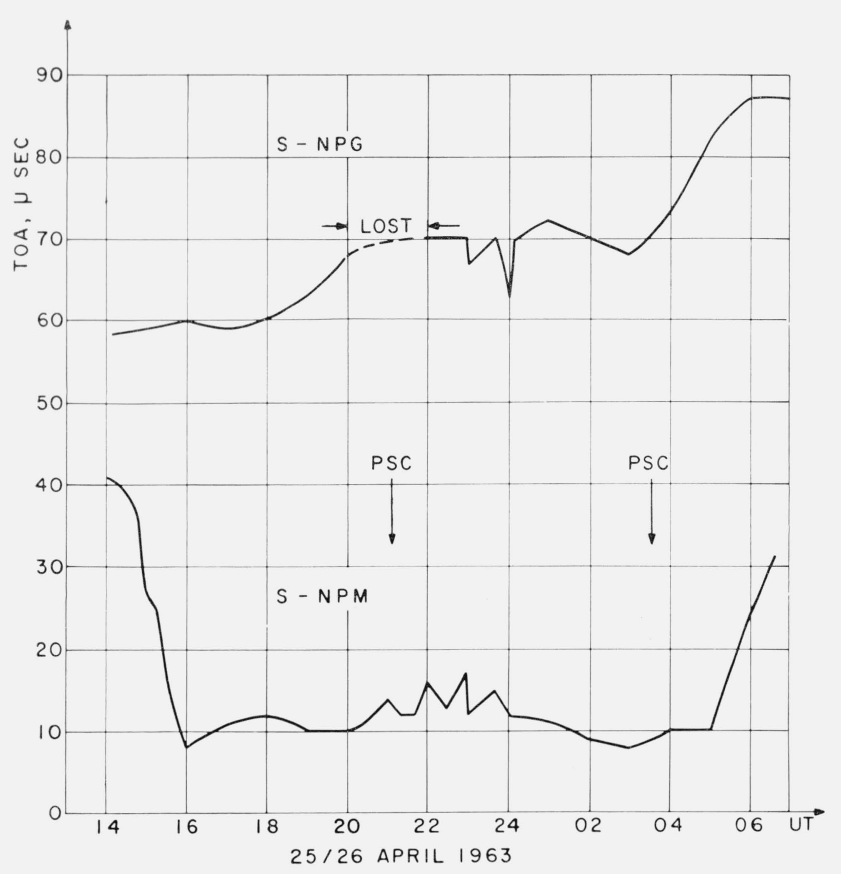

Figure 10. One form of typical effects of geomagnetic disturbances on VLF TOA recordings.

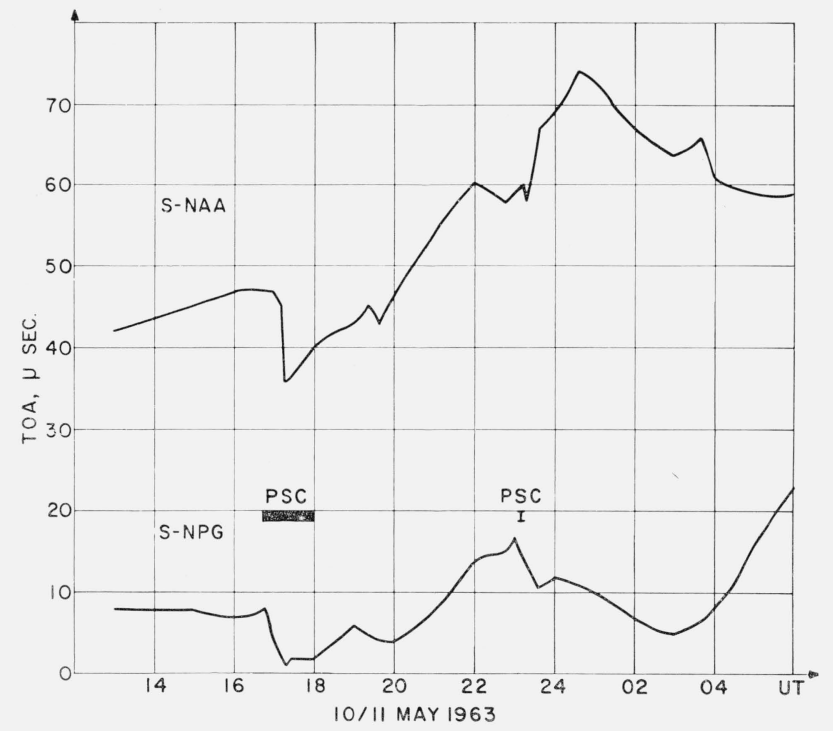

Figure 11. Another form of typical effects of geomagnetic disturbances on VLF TOA recordings.

VLF amplitudes seem to be less affected by magnetic and ionospheric perturbations as shown by a cursory analysis. Moreover, amplitude perturbations are more difficult to detect against the background of amplitude variations caused by the transmitter facilities. A more detailed analysis will be carried out later.

\section{Preliminary Kiruna Results}

Interesting results of some very recent VLF measurements at Kiruna are depicted in figures 13

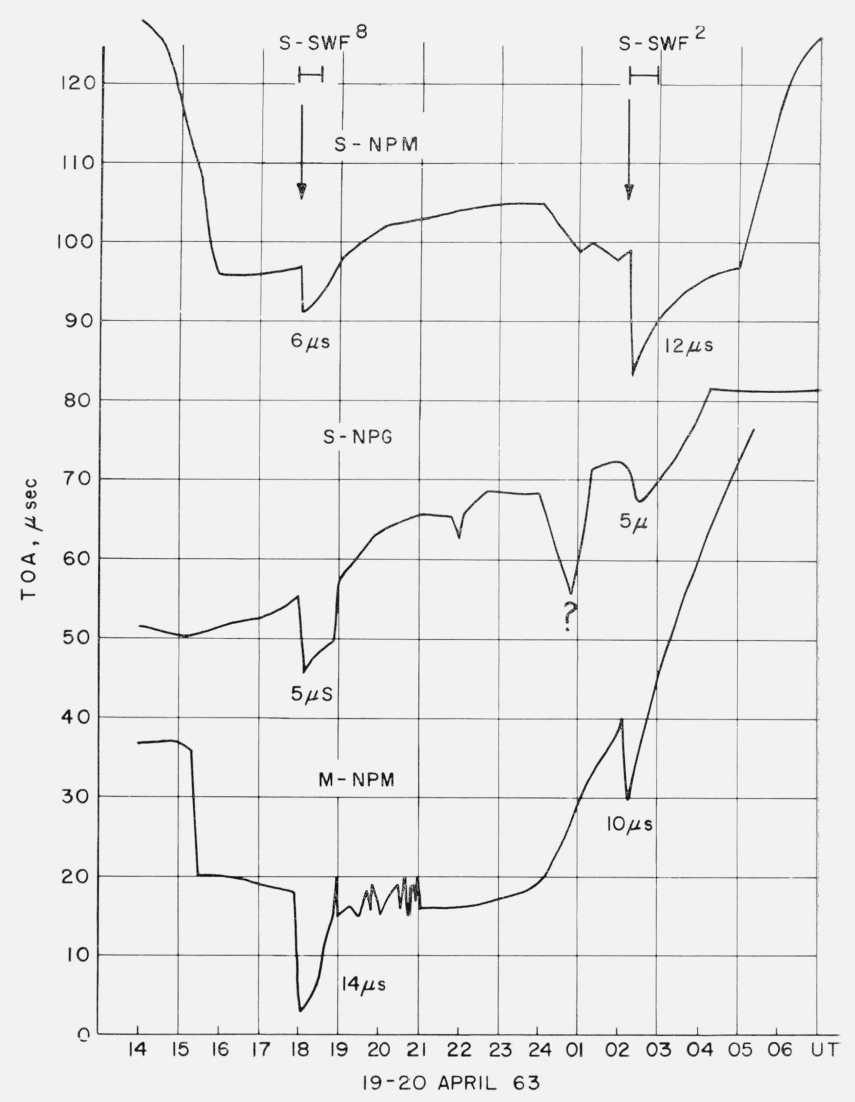

Figure 12. Typical effects of solar events on VLF TOA recordings.

and 14. Remarkable are the large amplitude dips of NSS signals of about $23 \mathrm{db}$ (fig. 13) occurring approximately $50 \mathrm{~min}$. before sunrise at the transmitter. We have observed these attenuation phenomena accompanied by dispersion-like phase behaviors (phase plateaus) always during sunrise along the $\mathrm{NPM} \rightarrow \mathrm{M}, \mathrm{NBA} \rightarrow \mathrm{K}$, and $\mathrm{NBA} \rightarrow \mathrm{S}$ transmission paths but almost never on Haiku $\rightarrow \mathrm{M}$ transmissions at frequencies of 10.2 and $14.2 \mathrm{kc} / \mathrm{s}$. A recent experiment with Haiku $\rightarrow \mathrm{M}$ on $17.2 \mathrm{kc} / \mathrm{s}$ indicated the appearance of amplitude dips and phase plateaus above that frequency. These experimental results are presently being compared with Crombie's theory [1963] of mode conversion and mode interierence. In this connection, it should be mentioned that highaltitude nuclear tests have sometimes shown the tendency to wash out the $\mathrm{NPM} \rightarrow \mathrm{M}$ phase plateaus during the day(s) following a blast.

Figure 14 gives a comparison of the NBA TOA measurements at Kiruna and Stockholm on 24/25 June and the correlation of phase anomalies with sudden cosmic noise absorption (SCNA) phenomena indicated by the Kiruna riometer. The two NBA paths have practically the same length of $9,500 \mathrm{~km}$. It is not certain whether the large discrepancy of $19 \mu$ sec of the diurnal TOA shifts can be explained alone by the difference of day to night proportions 


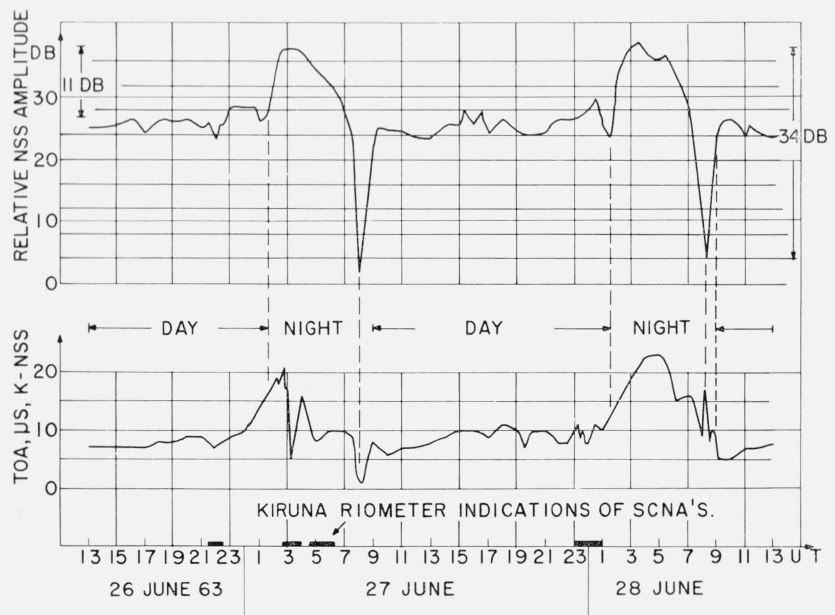

Figure 13. Typical diurnal TOA and amplitude patterns of NSS signals recorded at Kiruna between 26 and 28 June 1963.

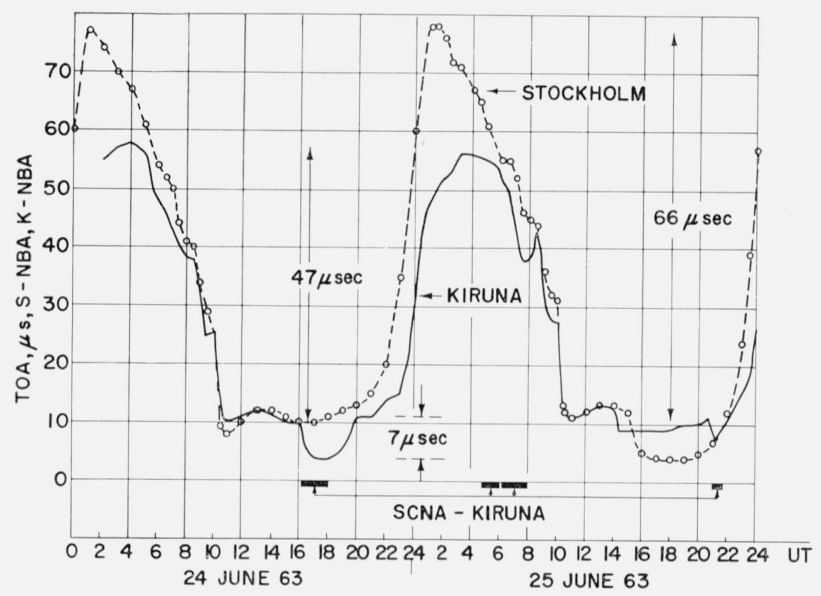

Figure 14. Diurnal TOA patterns of NBA recorded simultaneously at Stockholm and Kiruna between 24 and 25 June 1963 , showing coincidence of VLF phase anomalies with SCNA events indicated by a riometer at Kiruna Geophysical Observatory.

of the propagation paths. The availability of additional data by the end of summer will shed more light on this matter. The figures show also that the Kiruna riometer indications of SCNA events coincided with the $\mathrm{NBA} \rightarrow \mathrm{K}$ TOA effect at about 1600 on 24 June. But there was no riometer indication of such an event at 1420 on 25 June when $\mathrm{NBA} \rightarrow \mathrm{K}$ showed a weak and NBA $\rightarrow$ S a strong phase anomaly.

\section{Conclusions}

VLF phase and amplitude measurements at Stockholm on NPM and NPG during the first half of 1963 have revealed a reasonable correlation between VLF phase anomalies and geomagnetic phenomena. It is suspected that most of the as yet unexplained phase anomalies were caused by aurorae. Amplitude effects were usually smaller or not clearly detectable. The precision of standard frequency transfer via an Arctic VLF path was found to be within a factor of 2 of the precision attained with other transmissions. Diurnal TOA changes for Arctic VLF paths are complicated because of peculiar path illumination conditions but can be readily explained. However, no explanation has been found yet for the excessive diurnal amplitude variations along the $\mathrm{NPG} \rightarrow \mathrm{S}$ path.

It is a pleasure to acknowledge the assistance by our Laboratory directors, in particular by Mr. P. O. Lundbom, Director of Research, FOA; the vital help in electronic instrumentation and measurements furnished enthusiastically by Y. Ericsson, B. Selin, and E. Cassel, FOA, and J. Hargrave, USAELRDL; the supply of ionospheric and geomagnetic data by Dr. R. Lindquist and Mr. T. Sanden, FOA; the splendid hospitality of the Director and staff of the Kiruna Geophysical Observatory; and the excellent cooperation of Mr. F. Brand, USAELRDL.

\section{References}

Adams, R. M., and H. A. Whitehead (May 1960), Daytwilight-night charts for the Northern hemisphere, Defense Research Laboratory, University of Texas.

Chilton, C. J., D. D. Crombie, and A. G. Jean (1962), Phase variations in VLF propagation, Proc. AGARD-1962 (in press).

Crombie, D. D. (Jan. 1964), Periodic fading during sunrise and sunset on long VLF paths, Symposium on ionospheric propagation of VLF radio waves, Boulder, Colo. Aug. 1963, Radio Sci. J. Res. NBS/USNC-URSI 68D, No. 1, 27-34.

Reder, F. H. (July-Aug. 1963), Achievements and problem areas of atomic frequency control, Frequency 1, 32-45.

Seeley, E. W. (March 1963), Two and three-loop superdirective receiver antennas, J. Res. NBS 6rD (Radio Prop.), No. 2, 215.

Wait, J. R. (1962), Ch. VII, Electromagnetic Waves in Stratified Media (Pergamon Press, Oxford, and Macmillan Co., New York, N.Y.).

(Paper 68D3-342) 